\title{
Vapochromism of Organic Crystals Based on Macrocyclic Compounds and Inclusion Complexes
}

\author{
Toshikazu Ono *(D) and Yoshio Hisaeda * \\ Department of Chemistry and Biochemistry, Graduate School of Engineering, Center for Molecular \\ Systems (CMS), Kyushu University, 744 Motooka, Nishi-ku, Fukuoka 819-0395, Japan \\ * Correspondence: tono@mail.cstm.kyushu-u.ac.jp (T.O.); yhisatcm@mail.cstm.kyushu-u.ac.jp (Y.H.)
}

Received: 28 October 2020; Accepted: 18 November 2020; Published: 19 November 2020

\begin{abstract}
Vapochromic materials, which change color and luminescence when exposed to specific vapors and gases, have attracted considerable attention in recent years owing to their potential applications in a wide range of fields such as chemical sensors and environmental monitors. Although the mechanism of vapochromism is still unclear, several studies have elucidated it from the viewpoint of crystal engineering. In this mini-review, we investigate recent advances in the vapochromism of organic crystals. Among them, macrocyclic molecules and inclusion complexes, which have apparent host-guest interactions with analyte molecules (specific vapors and gases), are described. When the host compound is properly designed, its cavity size and symmetry change in response to guest molecules, influencing the optical properties by changing the molecular inclusion and recognition abilities. This information highlights the importance of structure-property relationships resulting from the molecular recognition at the solid-vapor interface.
\end{abstract}

Keywords: vapochromism; fluorescence; macrocycles; inclusion crystals; host-guest chemistry

\section{Introduction}

The development of chemosensors has been the subject of intensive research for potential applications in various fields covering human health, industries, and security fields. Gas chromatography, high-performance liquid chromatography, and electrochemical sensing are commonly used for the detection of small molecules and volatile organic compounds. However, most of these methods fail to meet the requirements of simple operation and are expensive. In this context, vapochromic materials that undergo color and/or fluorescence changes in response to specific gases and vapors have been a promising phenomenon. Colorimetric sensor arrays with pattern recognition capabilities have been widely used to detect and discriminate multiple chemically similar samples.

In the last decades, vapochromic materials based on organic dyes, metal complexes, metal organic frameworks, and covalent organic frameworks have attracted a lot of attention and various researches have been carried out. Various metal complexes are known to show vapochromism in the solid-states due to the significant changes in the metal-to-metal interaction and coordination bonding modes caused by the adsorption and desorption of vapor molecules. Several examples of metal-containing vapochromic materials such as $\mathrm{Pt}(\mathrm{II})$ or $\mathrm{Au}(\mathrm{I})$ have been reported and compiled in review papers [1-6]. On the other hand, metal-free vapochromic materials have been recently considered. The purpose of this mini-review is to investigate recent advances in the fields of vapochromism/vapofluorochromism of organic materials, especially focusing on host-guest compounds with distinct mechanisms and where structural identification has been achieved. 


\section{Vapochromic Materials Based on Macrocyclic Compounds}

Macrocyclic compounds have long been known as host compounds, and cyclodextrins [7], calixarenes [8], thiacalixarenes [9], pillararenes [10], and cucurbiturils [11] have been reported. Some of them incorporate guest molecules into the cavity of their cyclic framework via intermolecular interactions to form a host-guest complex in solution and the solid-states. For example, the room-temperature phosphorescence from guest molecules has been observed when cyclodextrin derivatives and halogenated naphthalene are used as host compounds and guest molecules, respectively [12]. This is because the formation of the host-guest complex can suppress thermal deactivation. Thus, the formation of complexes, such as host-guest complexes, has been important for expressing hidden optical functions.

Macrocyclic compounds have internal cavities based on their molecular shape. If the size of the guest molecule does not match the size of the cavities, it will not be incorporated into the cavities. If the guest molecule matches the size of the cavities, it will be selectively incorporated into the cavities. These molecular recognition capabilities have been used to retain and remove substances and for sustained release materials. Based on this phenomenon, various sensor materials have been developed as molecular recognition membranes by combining with electrochemical sensors [13]. Research on vapochromism, in which the host compound is a solid and the guest compound is a vapor (gas), attracts great attention because of the absorption and luminescence response before and after the adsorption of the guest molecule. These studies have widely used porous materials as hosts that can adsorb gases and small organic compounds as guests. Among them, studies in which the crystal structures have been identified before and after guest adsorption are essential to discuss the mechanism of vapochromism. Recently, vapochromic materials based on pillar[n]arene derivatives, which are host compounds with a cyclic structure, have been of great interest.

Pillar[n]arenes, reported by Ogoshi in 2008 [14], are macrocyclic molecules composed of 1,4-di-alkoxybenzene, which are called pillar[5]arene or pillar[6]arene, etc., depending on the repeating unit " $n$ ". Research progress with these compounds has been rapidly expanded and has been summarized in some review papers regarding supramolecular complexes and host-guest chemistry $[10,15,16]$. In this mini-review, we present various vapochromic materials based on host-guest chemistry inspired by the unique structures of pillar[n]arenes and their related compounds.

The difference between the pillar[5]arene and the pillar[6]arene is the size of the cavity. The cavity size of pillar[5]arenes and pillar[6]arenes is ca. 4.7 and ca. $6.7 \AA$, respectively. The pillar[5]arene tends to incorporate linear chain hydrocarbons via $\mathrm{CH}-\pi$ interactions, whereas the pillar[6]arene tends to accommodate larger molecules such as aromatic molecules and cyclic alkanes. This cavity size-dependent selectivity of the guest molecule makes it possible to fractionate positional substitutes in organic compounds. For example, it has been reported that these materials can be used to separate styrene from ethylbenzene and to separate three xylene isomers $[17,18]$. Separation of linear and branched alkanes is demonstrated using the host-guest chemistry of pillar[n]arenes as well [19]. However, the color of the solid powder of a typical pillar[n]arene is white, making it difficult to visually detect the uptake event of the guest molecules, for example, by color-change. To overcome these problems, Ogoshi et al. [20] used a novel macrocyclic molecule in which an electron-accepting molecule, benzoquinone, was introduced into the molecular structure of the pillar[5]arene (1) (Figure 1). This material (1) was brown-color in the absence of any guest molecules. The color of the material changed from brown to light-red when linear alkane vapors were introduced, indicating that the alkane vapors, which had been challenging to detect due to the color change, were successfully detected with the naked eye. Uptake of methanol vapor induced a different color change, from brown to black. It was also found that branched and cyclic alkane vapors did not show a color change when exposed to them. Furthermore, when a mixture of linear, cyclic, and branched alkane vapors was used, it was found that the gas selectively adsorbed linear alkane vapors and showed a color change. In other words, it is possible to detect the presence of linear alkane gas molecules in the mixed alkane gas by the color 
change. Recently, Ogoshi et al. [21] investigated vapochromic behaviors of pillar[6]arene with one benzoquinone unit to detect various small aromatic guests vapors.
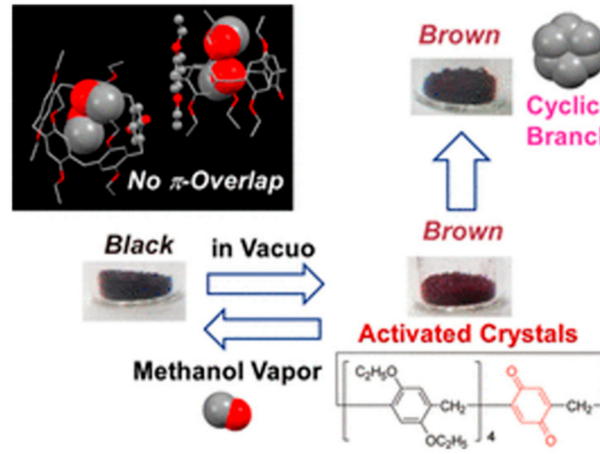

1
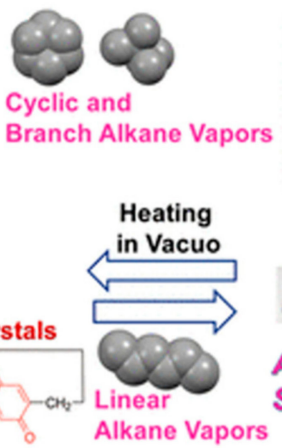

Alkane Vapors

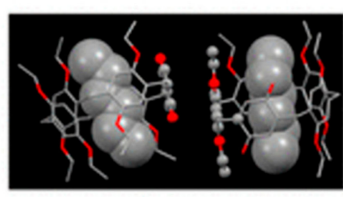

Red

Partial $\pi$-Overlap

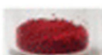

Alkano-Shape

Selective Vapochromism

Figure 1. Vapochromic behavior of $\mathbf{1}$ against various alkane vapors and methanol vapors. Reproduced with permission from Reference [20]. Copyright 2017 American Chemical Society.

Vapochromic materials have been reported to be scalable to various guest molecules based on molecular design. Huang et al. [22] changed the analytes to volatile aliphatic aldehydes and investigated their vapochromic behaviors using 1 (Figure 2). Aliphatic aldehydes are selected as target compounds because they are generally highly reactive in nature and are potentially hazardous volatile organic compounds that are considered unfavorable effects on the environmental and human health. Exposure of guest-free crystals to various types of aliphatic aldehyde vapors resulted in quantitative adsorption of these aldehyde vapors and different color changes were observed. Comparison of the single-crystal structures revealed that different types of aldehyde vapors led to change in the relative positions of the adjacent 1,4-diethoxybenzene and benzoquinone units. As a result, the charge-transfer (CT) interactions between the electron-rich 1,4-diethoxybenzene and electron-deficient benzoquinone units were altered, resulting in vapochromic behaviors with different color changes. These behaviors were regenerated by the heat treatment and were able to repeatedly observe guest adsorption and desorption without any particular loss of performance.

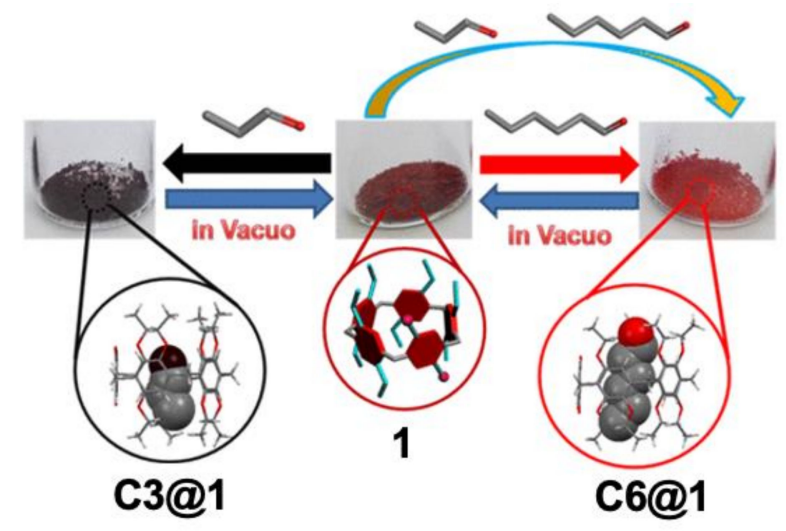

Figure 2. Vapochromic behavior of $\mathbf{1}$ against aliphatic aldehydes vapors. Reproduced with permission from Reference [22]. Copyright 2018 American Chemical Society.

Subsequently, Ogoshi et al. [23] investigated the creation of a vapochromic material using a unique mechanism that changes its liquid-to-solid state when exposed to specific vapors based on pillar[6]arene derivatives (2) (Figure 3). By attaching $12 n$-hexyl $\left(\mathrm{C}_{6} \mathrm{H}_{13}\right)$ chains to pillar[6]arene, this system was transformed into a room-temperature structural liquid, that is, a nanoscale system with some order but no periodic structure. This clear liquid has the characteristic of becoming turbid solid when exposed to 
guest vapors for several seconds. In particular, the state changes are expected to apply to new vapor detection systems due to the selectivity of vapors, such as cyclohexane. Powder X-ray diffraction (PXRD) measurements supported the fact that the linear $n$-hexyl group was initially contained in the cavity of pillar[6]arene, but the uptake of the cyclohexane guest vapor results in the de-threading of the $n$-hexyl group. This is because the cavity size of pillar[6]arene is more suitable for cyclohexane than linear alkyl chains. The guest inclusion behaviors were also confirmed by proton NMR measurements.

(a)

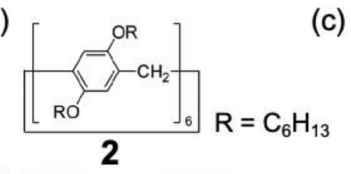

(b)

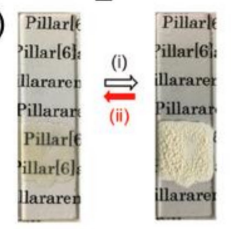

(c)

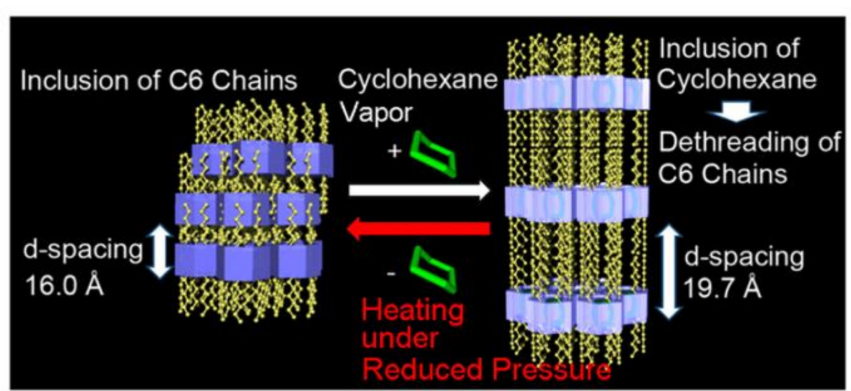

Figure 3. (a) Chemical structure of 2. (b) Photographs of 2 by (i) exposing structural liquid 2 to cyclohexane vapor at $25^{\circ} \mathrm{C}$ for $30 \mathrm{~min}$ and (ii) heating the solid 2 at $80{ }^{\circ} \mathrm{C}$ under reduced pressure for $30 \mathrm{~min}$. (c) Schematic illustration of the guest vapor-induced state change of 2 . Reproduced with permission from Reference [23]. Copyright 2019 American Chemical Society.

To improve the vapochromic properties of pillar[n]arenes, direct modification of fluorophore in their molecular skeleton has also been reported. Huang et al. [24] proposed a novel macrocyclic molecule, in which an anthracene moiety was introduced in a part of pillar[5]arene (3) (Figure 4). Upon exposure of this material to vapors of various ketone with different alkyl chains (C3-C8), the compound showed unique vapochromic/vapofluorochromic behavior, as shown in Figure 4c. For example, after exposure to C4, C5, and C6, the anthracene moieties exist as monomers in the solid-state. In contrast, after exposure to $\mathrm{C} 7$ and $\mathrm{C} 8$, the anthracene moieties effectively form excimers in the solid-states. Single-crystal structures and PXRD experiments suggested that two types of anthracene assemblies, H-aggregation for fluorescence of excimer and J-aggregation for fluorescence of monomer, were found to exhibit different vapochromic properties.
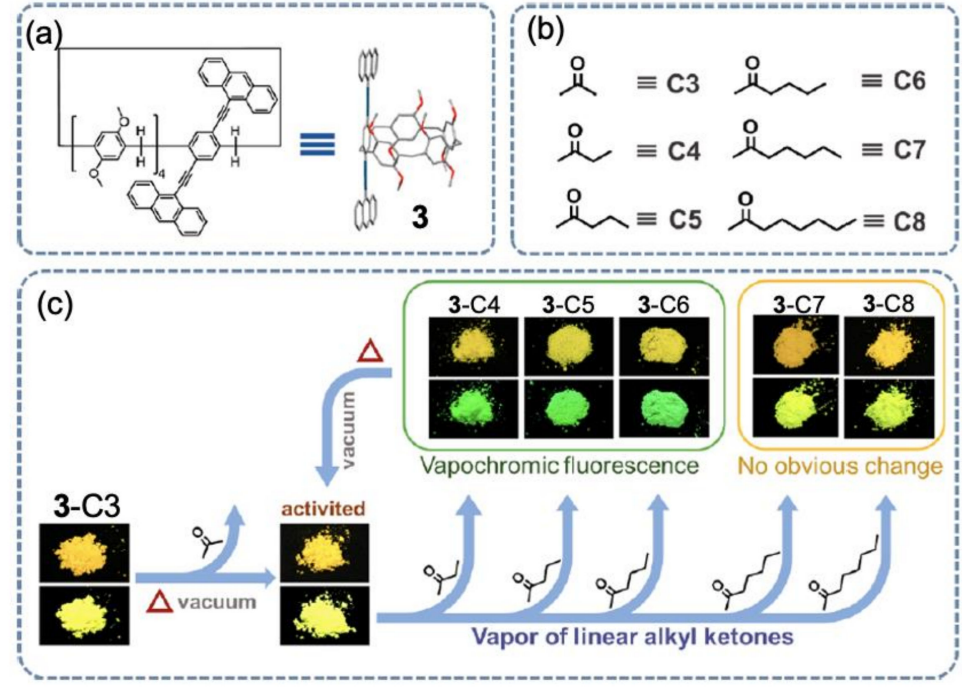

Figure 4. (a) Chemical structure and crystal structure of 3. (b) Chemical structures of ketones (C3-C8). (c) Schematic illustration of activation and vapochromic/vapofluorochromic behaviors of 3 . Reproduced with permission from Reference [24]. Copyright 2019 American Chemical Society. 
Another example of pillararenes modification with a fluorescent material is the so-called BowtieArene, which consists of a tetraphenylethylene (TPE) fluorophore and two pillar[5]arenes [25]. This figure-of-eight macrocycle material exhibits unique multi-stimuli-responsive fluorescence accompanied by vapor absorption with host-guest interactions.

It has also been reported that vapochromic properties can be found using pillar[n]arene without fluorescent tags. For example, Ogoshi et al. [26] reported that pillar[6]arene showed vapofluorochromism against benzonitrile, methyl benzoate, and divinylbenzene by crystal-state host-guest complexation at the solid-vapor interface. Li et al. [27] proposed the co-crystallization approach to demonstrate vapochromic materials (Figure 5). The red-colored co-crystals $(4 \bullet 5)$ were prepared by slow evaporation of the tetrahydrofuran-saturated solution of 4 and 5 . The red coloration was caused by intermolecular CT interactions between the electron-rich 4 and electron-deficient 5 with absorption at $452 \mathrm{~nm}$. However, after the co-crystals $(4 \bullet 5)$ were smashed to power and activated by heating at $70{ }^{\circ} \mathrm{C}$ under vacuum for $12 \mathrm{~h}$, the materials $(4 \bullet 5 \alpha)$ color changed to white. Exposure of $4 \bullet 5 \alpha$ to various vapors of haloalkane resulted in a color changes from white to a red or orange color. Such a combination of macrocycle/host-guest chemistry and co-crystal engineering offers great potential for further research.

(a)

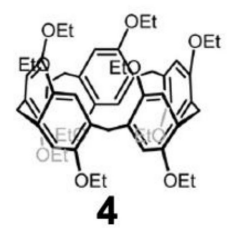

(b)

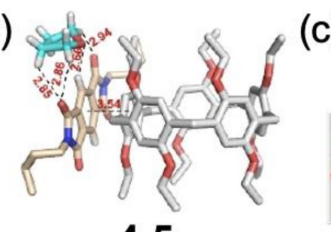

$4 \cdot 5$

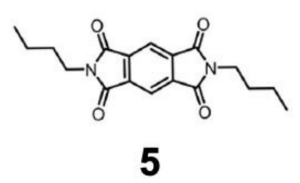

(c)

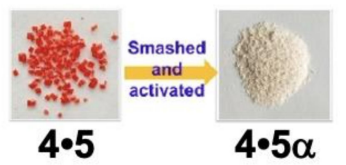

(d)

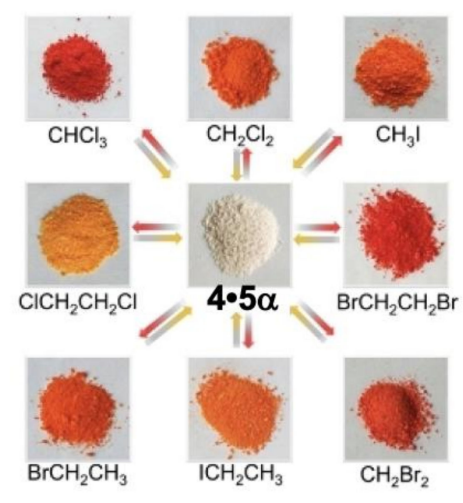

Figure 5. (a) Chemical structures of 4 and 5. (b) Crystal structure of $4 \bullet 5$. (c) Pictures of $4 \bullet 5$ and $4 \bullet 5 \alpha$. (d) Vapochromic behavior of $4 \bullet 5 \alpha$ against various vapors. Reproduced with permission from Reference [27]. Copyright 2016 Wiley-VCH.

Following these trends, it is possible to design various vapochromic materials in which changes in absorption and luminescence properties are induced by the uptake of guests, adding a new twist to the macrocyclic that function as host molecules. In particular, those with an apparent crystal structure allow for a detailed evaluation of host-guest interactions. Research is being carried out on how host molecules with what structures exhibit vapochromic properties.

\section{Vapochromic Materials Based on Inclusion Crystals}

The guest inclusion phenomenon is frequently observed in many organic compounds' crystallization process, regardless of the cyclic compounds mentioned above. This is because organic compounds have complex structures in three dimensions. For example, organic compounds with bulky and rigid substituents tend to include guest molecules because they do not pack easily without guests [28-31]. This suggests that a phenomenon may be found in which the packing structure changes depending on the type of guest, resulting in a change in optical properties. Indeed, inclusion crystals consisting of organic dyes as host molecules and various guest molecules have been reported. Most of them have been studied to modulate solid-state optical properties by changing the packing structure depending on the type of guest molecules. If this phenomenon allows the preparation of host-guest complexes through the solid-gas interface, it can cause vapochromism. The evaluation of the crystal 
structure of the host-guest complexes provides important information to discuss the mechanism of vapochromism.

In 2010, Naota et al. [32] proposed the first vapochromic organic crystals based on naphthalenediimide (NDI) derivatives (Figure 6). They designed S-shaped NDI derivatives bearing two pyrrole-imine tethers via an alkyl chain (6). The NDI moiety is an electron-deficient $\pi$-conjugated molecule that forms CT complex with electron-rich pyrrole-imine moieties and exhibits absorption and coloration in the visible light region. It has been found that the coloration of this material changes when various solvent molecules are incorporated as guests into the material's cavities due to a shift in the relative position of the NDI moiety and the pyrrole-imine tethers, resulting in a change in the CT interaction and coloration.

(a)

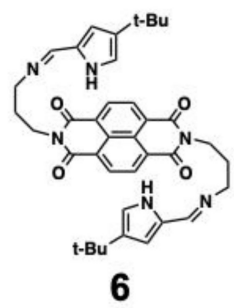

(b)

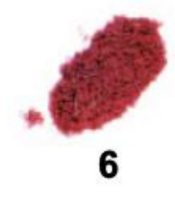

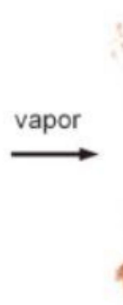

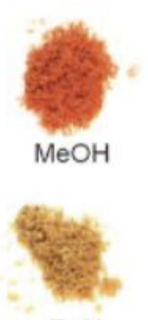

$\mathrm{Et}_{3} \mathrm{~N}$

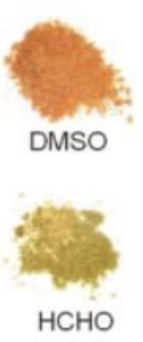

Figure 6. (a) Chemical structures of 6. (b) Vapochromic behavior of 6 against various vapors.

In 2016, we investigated the vapochromic behavior of NDI derivatives bearing two tris(pentafluorophenyl)borane units (7) (Figure 7) [33,34]. The luminescence intensity of the supramolecular host was weak, but it increased by 76, 46, and 37 times under saturated vapor pressure in response to vapors of toluene, benzene, and $m$-xylene, respectively. On the other hand, no increase in luminescence intensity was observed for the vapors of methanol, ethanol, acetone, dichloromethane, chloroform, hexane, and cyclohexane, although adsorption of molecules was observed. The guest-dependent color and fluorescence changes which were observed, attributed to intermolecular CT interactions between the electron-deficient NDI, and the electron-rich aromatic guest molecules were observed. These results show that vapochromic/vapofluorochromic behaviors against aromatic compounds can be achieved by host-guest interaction at the solid-vapor interface.

(a)

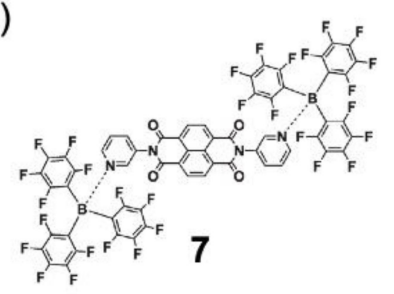

(b)

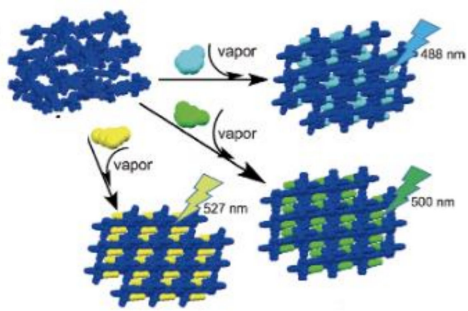

(c)

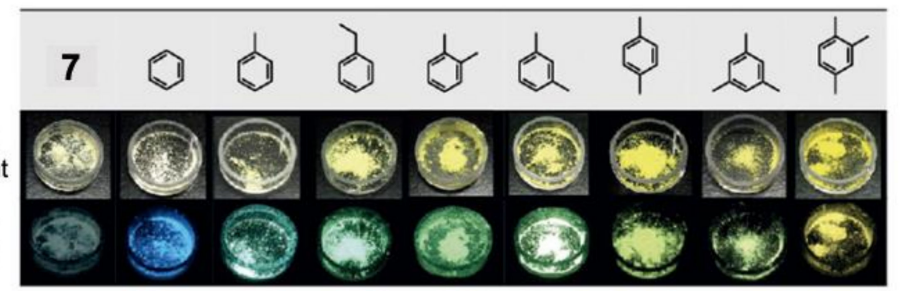

Figure 7. (a) Chemical structure of 7. (b) Guest inclusion behavior of 7 against vapors of guest molecules. (c) Photographs of $\mathbf{7}$ and $\mathbf{7}$ with exposure of guest vapors under daylight (upper row) and under ultraviolet-light (365 nm, bottom row). Reproduced with permission from Reference [34]. Copyright 2016 Wiley-VCH. 
Based on these findings, we systematically varied the side chains of NDI derivatives (8-10) and evaluated the vapochromic behaviors (Figure 8) [35,36]. Among them, NDI with a 2-benzophenone unit (8) showed a vapochromic/vapofluorochromic behavior toward toluene, $p$-xylene, 4-fluorotoluene, and anisole. The detection limits for toluene and $p$-xylene vapors are 10 parts-per-billion (ppm) and $20 \mathrm{ppm}$, respectively. From the single-crystal structures obtained from recrystallization, it was found that the guest molecules were incorporated in the space of the host framework to form a CT complex. This suggests that the absorption and fluorescence behavior is dependent on the type of guest molecule incorporated in the crystal. On the other hand, NDI with a diphenylmethane unit and NDI with a 3,5-di-tert-butylbenzene unit as substituents did not exhibit vapochromic behavior. This means that modification of side-chain structure of NDIs can be devised to achieve novel vapochromic/vapofluorochromic materials without significantly changing the electronic properties of the compounds. Modification of the solid-state structure plays an important role in the development of molecular recognition of the solid-vapor interface between sensor materials and the analytes. In addition, two sensor ensembles ( 7 and 8 ) have been combined to create a mini-sensor array used to identify small aromatic compounds containing benzene, toluene, and xylene isomers with the naked eye.

(a)
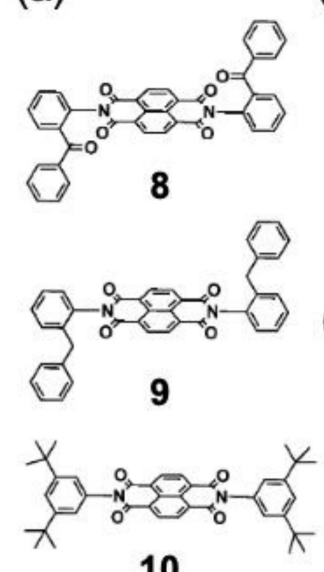

(b)

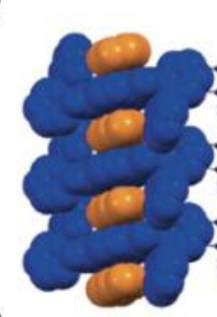

(c)

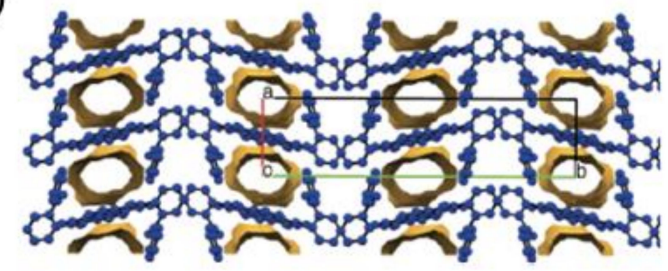

(d)

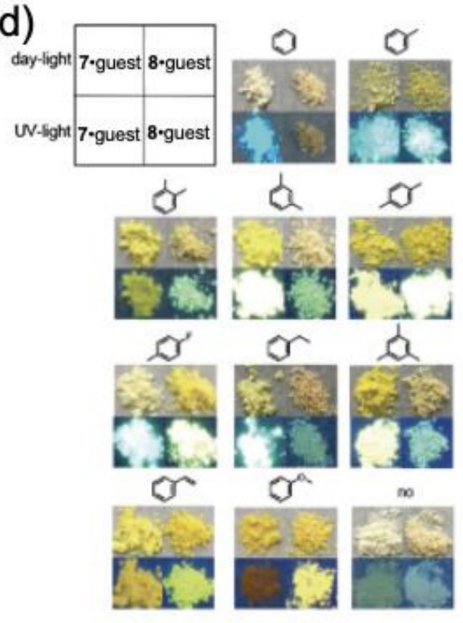

Figure 8. (a) Chemical structures of 8-10. (b) Crystal structure of 8 including anisole as a guest molecule. (c) Visualization of calculated voids and contact surface maps of 8. (d) Vapochromic bahavior of 7 and $\mathbf{8}$, and $\mathbf{7}$ and $\mathbf{8}$ after exposing guest vapors for 1 day.

The introduction of bulky substituents of dyes is essential to create porous crystals that can act as vapochromic materials. For example, Yang et al. investigated porous organic crystals by modifying the $\mathrm{H}$-shaped pentiptycene scaffold of dyes and have been applied as vapochromic materials [37,38]. The pentiptycene unit is well known as a rigid-bulky substituent [39] so that aggregation-induced fluorescence quenching is minimized and pore volume accessible to guest molecules is created.

Porous crystals can also be prepared by dendron modification of dyes and have been applied as vapochromic materials. In 2020, Takeda et al. [40] studied porous organic crystals consisting of $\pi$-conjugated molecules with multibranched carbazole units as dendritic propeller sites (11) (Figure 9). It was found that these crystals can capture and release water molecules from the atmosphere. Also, the apparent color of the crystalline powder changes is readily detectable with the naked eye. For example, at room-temperature $\left(25^{\circ} \mathrm{C}\right)$, the crystals are yellow when the humidity is below $40 \%$, but they turn entirely red when they reach $50 \%$. This color change is reversible in response to humidity changes, and the humidity and temperature in which the color change occurs are close to our living environment. Thus, crystals can be used as high-performance sensors or adsorbates under water-containing conditions. 
(a)

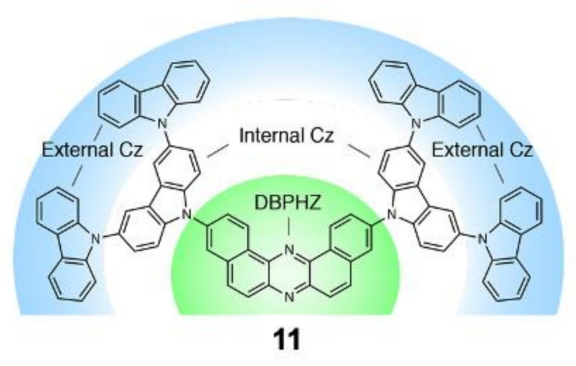

(b)

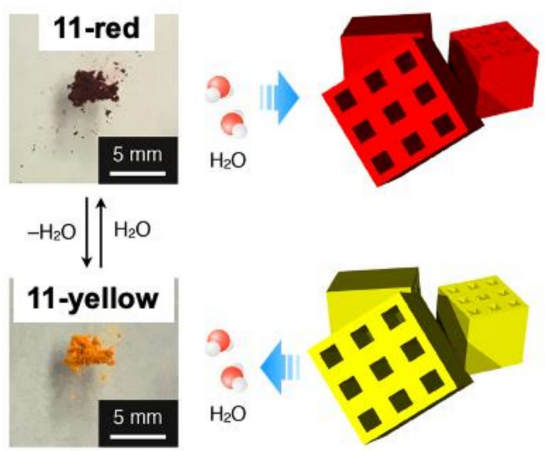

Figure 9. (a) Chemical structure of 11. (b) Photographs of vaphochromic behavior of 11 upon uptake/release of water molecules. Reproduced with permission from Reference [40]. Copyright 2020 Nature publishing group.

Vapochromism of organic crystals using intramolecular proton transfer has been reported. Uekusa et al. [41] suggested that 5-aminoisophthalic acid (12) exhibited a reversible color change upon exposure to solvent vapors via a pseudopolymorphic transformation between pink hemihydrate and yellow anhydrous crystals (Figure 10). When exposed to solvent vapors such as methanol, ethanol, and acetonitrile, the white crystals gradually turn into yellow anhydrous crystals, and they revert to hemihydrate crystals in the presence of water. Crystal structural analysis suggested that in the crystal structure of the hemihydrate form, carboxylate anion $\left(\mathrm{COO}^{-}\right)$and ammonium cation $\left(\mathrm{NH}^{3+}\right)$ were formed through proton transfer to form a zwitterion. On the other hand, in the non-hydrated state, the amino group remains in the form of $\mathrm{NH}_{2}$ conformation, and the compound $\mathbf{1 2}$ is in a nonionic state with no proton transfer. The protonation and deprotonation of the carboxylate group has been assigned by observing the twisting of the group against the plane of the aromatic ring. Stimulated by solvent vapors, the compound $\mathbf{1 2}$ undergoes the dehydration/hydration conversion, resulting in a vapochromic behavior with a significant impact on the proton transfer behavior. The similar strategy was also reported by the same group using pimemidic acid [42].

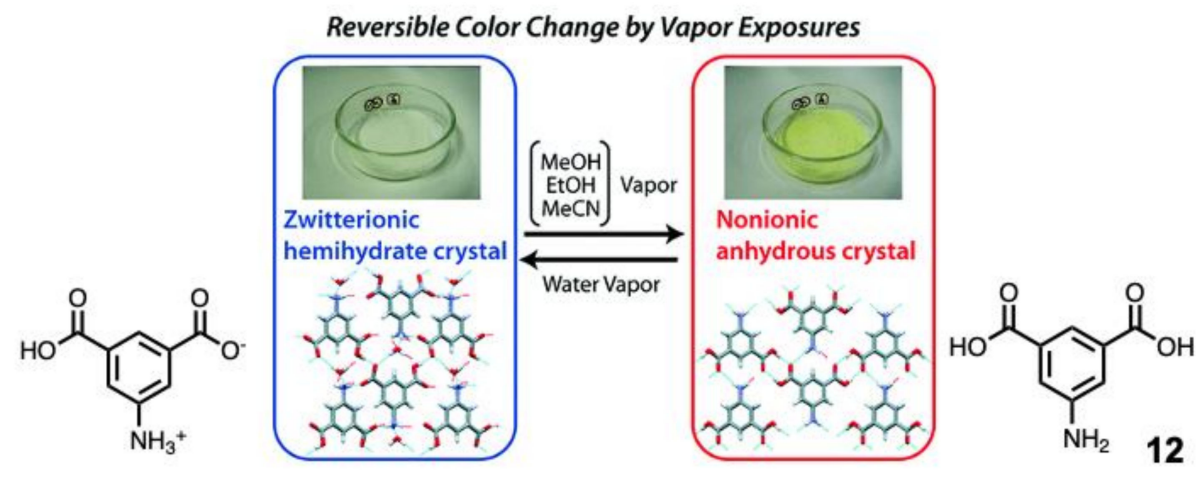

Figure 10. Vapochromic behavior of 12. Reproduced with permission from Reference [41]. Copyright 2019 American Chemical Society.

In 2019, we investigated [43] the vapochromism of organic crystals using intermolecular proton transfer of acid-base complexes. To do this, three crystals, salts, cocrystal, and salt-cocrystal continuum, were designed by $\mathrm{pK}_{\mathrm{a}}$ values of acids and bases (Figure 11). The structure-property relationships of crystals were well studied to realize the regulation of proton transfer dynamics between acid-base complexes by photoluminescence color change. An acid-base complex consisting of a pyridine-modified pyrrolopyrrole dye with salicylic acid $(\mathbf{1 3 \bullet 1 4})$, categorized as a salt-cocrystal continuum, undergoes vapochromism against vapors of dichloromethane. The luminescent color change is attributed to modulation of the degree of protonation by alternating the crystal packing environment upon inclusion 
and desorption of dichloromethane. When the complex was fumed with triethylamine (TEA) vapor for $1 \mathrm{~h}$, the emission color changed to blue. The emission color change originated from deprotonation of 13 by TEA vapor.

(a)
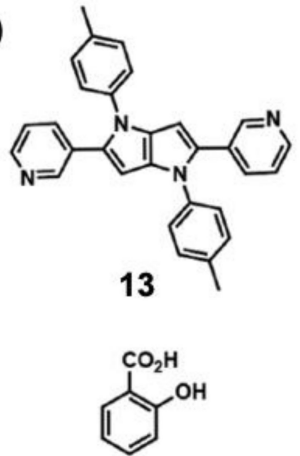

14 (b)
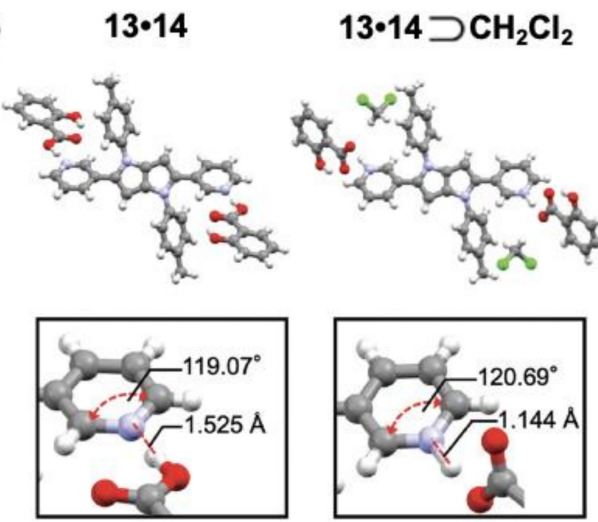

(c)

TEA vapor

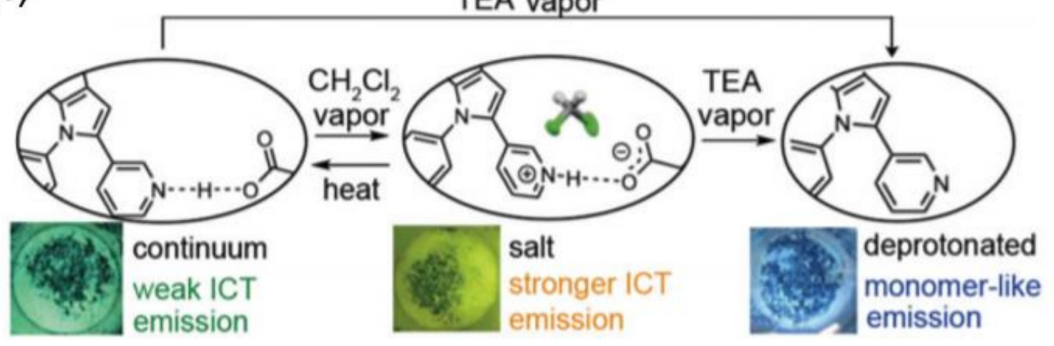

Figure 11. (a) Chemical structures of $\mathbf{1 3}$ and 14. (b) Crystal structure of acid-base complex $(\mathbf{1 3 \bullet 1 4})$ and its $\mathrm{CH}_{2} \mathrm{Cl}_{2}$ included structure. (c) Schematic illustration of emission color tuning by various vapor molecules.

\section{Conclusions}

Vapochromic materials based on host-guest chemistry at the solid-gas interface have been extensively studied. In the first part, we focused on the pillararene derivatives among the macrocyclic molecules as hosts. We introduced their guest-recognition abilities depending on the size of the intrinsic ring framework. Modification of the macrocyclic molecules allows the rational design of vapochromic materials and studies on creating rational vapochromic materials and their mechanisms. In the latter part, we introduced various vapochromic materials, focusing on the fact that the inclusion crystal is a host-guest complex. The importance of introducing appropriately bulky substituents into the dye molecules and a new mechanism of vapochromic materials, in which proton transfer changes in response to guest vapors, were introduced. It is expected that the creation of vapochromic materials will continue through various molecular materials and complexes. We believe that the future of these studies has the potential to be applied to artificial olfactory systems that can outperform the olfactory capabilities of living organisms.

Author Contributions: Both authors contributed to this publication. All authors have read and agreed to the published version of the manuscript.

Funding: This research was funded by JSPS KAKENHI, grant numbers JP17H04875, JP20H04675, and JP20K21212.

Conflicts of Interest: The authors declare no conflict of interest. 


\section{References}

1. Kreno, L.E.; Leong, K.; Farha, O.K.; Allendorf, M.; Van Duyne, R.P.; Hupp, J.T. Metal-organic framework materials as chemical sensors. Chem. Rev. 2012, 112, 1105-1125. [CrossRef] [PubMed]

2. Zhang, X.; Li, B.; Chen, Z.-H.; Chen, Z.-N. Luminescence vapochromism in solid materials based on metal complexes for detection of volatile organic compounds (VOCs). J. Mater. Chem. 2012, 22, 11427-11441. [CrossRef]

3. Wenger, O.S. Vapochromism in organometallic and coordination complexes: Chemical sensors for volatile organic compounds. Chem. Rev. 2013, 113, 3686-3733. [CrossRef] [PubMed]

4. Zhou, X.; Lee, S.; Xu, Z.; Yoon, J. Recent Progress on the Development of Chemosensors for Gases. Chem. Rev. 2015, 115, 7944-8000. [CrossRef] [PubMed]

5. Kato, M.; Ito, H.; Hasegawa, M.; Ishii, K. Soft Crystals: Flexible Response Systems with High Structural Order. Chem. Eur. J. 2019, 25, 5105-5112. [CrossRef] [PubMed]

6. Li, E.; Jie, K.; Liu, M.; Sheng, X.; Zhu, W.; Huang, F. Vapochromic crystals: Understanding vapochromism from the perspective of crystal engineering. Chem. Soc. Rev. 2020, 49, 1517-1544. [CrossRef]

7. Crini, G. Review: A History of Cyclodextrins. Chem. Rev. 2014, 114, 10940-10975. [CrossRef]

8. Ikeda, A.; Shinkai, S. Novel Cavity Design Using Calix[n]arene Skeletons: Toward Molecular Recognition and Metal Binding. Chem. Rev. 1997, 97, 1713-1734. [CrossRef]

9. Morohashi, N.; Narumi, F.; Iki, N.; Hattori, T.; Miyano, S. Thiacalixarenes. Chem. Rev. 2006, 106, 5291-5316. [CrossRef]

10. Ogoshi, T.; Yamagishi, T.-A.; Nakamoto, Y. Pillar-shaped macrocyclic hosts pillar [n] arenes: New key players for supramolecular chemistry. Chem. Rev. 2016, 116, 7937-8002. [CrossRef]

11. Barrow, S.J.; Kasera, S.; Rowland, M.J.; del Barrio, J.; Scherman, O.A. Cucurbituril-Based Molecular Recognition. Chem. Rev. 2015, 115, 12320-12406. [CrossRef] [PubMed]

12. Li, D.; Lu, F.; Wang, J.; Hu, W.; Cao, X.M.; Ma, X.; Tian, H. Amorphous Metal-Free Room-Temperature Phosphorescent Small Molecules with Multicolor Photoluminescence via a Host-Guest and Dual-Emission Strategy. J. Am. Chem. Soc. 2018, 140, 1916-1923. [CrossRef] [PubMed]

13. Pirondini, L.; Dalcanale, E. Molecular recognition at the gas-solid interface: A powerful tool for chemical sensing. Chem. Soc. Rev. 2007, 36, 695-706. [CrossRef] [PubMed]

14. Ogoshi, T.; Kanai, S.; Fujinami, S.; Yamagishi, T.-A.; Nakamoto, Y. para-Bridged Symmetrical Pillar[5]arenes: Their Lewis Acid Catalyzed Synthesis and Host-Guest Property. J. Am. Chem. Soc. 2008, 130, 5022-5023. [CrossRef]

15. Ogoshi, T.; Tsuchida, H.; Kakuta, T.; Yamagishi, T.A.; Taema, A.; Ono, T.; Sugimoto, M.; Mizuno, M. Ultralong Room-Temperature Phosphorescence from Amorphous Polymer Poly(Styrene Sulfonic Acid) in Air in the Dry Solid State. Adv. Funct. Mater. 2018, 28. [CrossRef]

16. Jie, K.; Zhou, Y.; Li, E.; Huang, F. Nonporous Adaptive Crystals of Pillararenes. Acc. Chem. Res. 2018, 51, 2064-2072. [CrossRef]

17. Jie, K.; Liu, M.; Zhou, Y.; Little, M.A.; Bonakala, S.; Chong, S.Y.; Stephenson, A.; Chen, L.; Huang, F.; Cooper, A.I. Styrene Purification by Guest-Induced Restructuring of Pillar[6]arene. J. Am. Chem. Soc. 2017, 139, 2908-2911. [CrossRef]

18. Jie, K.; Liu, M.; Zhou, Y.; Little, M.A.; Pulido, A.; Chong, S.Y.; Stephenson, A.; Hughes, A.R.; Sakakibara, F.; Ogoshi, T.; et al. Near-Ideal Xylene Selectivity in Adaptive Molecular Pillar[n]arene Crystals. J. Am. Chem. Soc. 2018, 140, 6921-6930. [CrossRef]

19. Kakuta, T.; Yamagishi, T.-A.; Ogoshi, T. Stimuli-Responsive Supramolecular Assemblies Constructed from Pillar[n]arenes. Acc. Chem. Res. 2018, 51, 1656-1666. [CrossRef]

20. Ogoshi, T.; Shimada, Y.; Sakata, Y.; Akine, S.; Yamagishi, T.-A. Alkane-Shape-Selective Vapochromic Behavior Based on Crystal-State Host-Guest Complexation of Pillar[5]arene Containing One Benzoquinone Unit. J. Am. Chem. Soc. 2017, 139, 5664-5667. [CrossRef]

21. Wada, K.; Kakuta, T.; Yamagishi, T.-A.; Ogoshi, T. Obvious vapochromic color changes of a pillar[6]arene containing one benzoquinone unit with a mechanochromic change before vapor exposure. Chem. Commun. 2020, 56, 4344-4347. [CrossRef] [PubMed] 
22. Li, E.; Jie, K.; Zhou, Y.; Zhao, R.; Zhang, B.; Wang, Q.; Liu, J.; Huang, F. Aliphatic Aldehyde Detection and Adsorption by Nonporous Adaptive Pillar[4]arene[1]quinone Crystals with Vapochromic Behavior. Acs Appl. Mater. Interfaces 2018, 10, 23147-23153. [CrossRef] [PubMed]

23. Ogoshi, T.; Maruyama, K.; Sakatsume, Y.; Kakuta, T.; Yamagishi, T.-A.; Ichikawa, T.; Mizuno, M. Guest Vapor-Induced State Change of Structural Liquid Pillar[6]arene. J. Am. Chem. Soc. 2019, 141, 785-789. [CrossRef] [PubMed]

24. Li, Q.; Zhu, H.; Huang, F. Alkyl Chain Length-Selective Vapor-Induced Fluorochromism of Pillar[5]arene-Based Nonporous Adaptive Crystals. J. Am. Chem. Soc. 2019, 141, 13290-13294. [CrossRef]

25. Lei, S.-N.; Xiao, H.; Zeng, Y.; Tung, C.-H.; Wu, L.-Z.; Cong, H. BowtieArene: A Dual Macrocycle Exhibiting Stimuli-Responsive Fluorescence. Angew. Chem. Int. Ed. 2020, 59, 10059-10065. [CrossRef]

26. Ogoshi, T.; Hamada, Y.; Sueto, R.; Kojima, R.; Sakakibara, F.; Nagata, Y.; Sakata, Y.; Akine, S.; Ono, T.; Kakuta, T.; et al. Vapoluminescence Behavior Triggered by Crystal-State Complexation between Host Crystals and Guest Vapors Exhibiting No Visible Fluorescence. Cryst. Growth Des. 2020. [CrossRef]

27. Li, B.; Cui, L.; Li, C. Macrocycle Co-Crystals Showing Vapochromism to Haloalkanes. Angew. Chem. Int. Ed. 2020. [CrossRef]

28. Bishop, R. Designing new lattice inclusion hosts. Chem. Soc. Rev. 1996, 25, 311-319. [CrossRef]

29. Fei, Z.; Kocher, N.; Mohrschladt, C.J.; Ihmels, H.; Stalke, D. Single Crystals of the Disubstituted Anthracene 9, 10-(Ph2P $\square$ S) 2C14H8 Selectively and Reversibly Detect Toluene by Solid-State Fluorescence Emission. Angew. Chem. Int. Ed. 2003, 42, 783-787. [CrossRef]

30. Ooyama, Y.; Nagano, S.; Okamura, M.; Yoshida, K. Solid-State Fluorescence Changes of 2-(4-Cyanophenyl)-5-[4-(diethylamino)phenyl]-3H-imidazo[4,5-a]naphthalene upon Inclusion of Organic Solvent Molecules. Eur. J. Org. Chem. 2008, 2008, 5899-5906. [CrossRef]

31. Hinoue, T.; Miyata, M.; Hisaki, I.; Tohnai, N. Guest-Responsive Fluorescence of Inclusion Crystals with $\pi$-Stacked Supramolecular Beads. Angew. Chem. Int. Ed. 2012, 51, 155-158. [CrossRef] [PubMed]

32. Takahashi, E.; Takaya, H.; Naota, T. Dynamic vapochromic behaviors of organic crystals based on the open-close motions of S-shaped donor-acceptor folding units. Chem. Eur. J. 2010, 16, 4793-4802. [CrossRef] [PubMed]

33. Ono, T.; Sugimoto, M.; Hisaeda, Y. Multicomponent Molecular Puzzles for Photofunction Design: Emission Color Variation in Lewis Acid-Base Pair Crystals Coupled with Guest-to-Host Charge Transfer Excitation. J. Am. Chem. Soc. 2015, 137, 9519-9522. [CrossRef] [PubMed]

34. Hatanaka, S.; Ono, T.; Hisaeda, Y. Turn-On Fluorogenic and Chromogenic Detection of Small Aromatic Hydrocarbon Vapors by a Porous Supramolecular Host. Chem. Eur. J. 2016, 22, 10346-10350. [CrossRef]

35. Ono, T.; Tsukiyama, Y.; Taema, A.; Hisaeda, Y. Inclusion Crystal Growth and Optical Properties of Organic Charge-transfer Complexes Built from Small Aromatic Guest Molecules and Naphthalenediimide Derivatives. Chem. Lett. 2017, 46, 801-804. [CrossRef]

36. Ono, T.; Tsukiyama, Y.; Hatanaka, S.; Sakatsume, Y.; Ogoshi, T.; Hisaeda, Y. Inclusion crystals as vapochromic chemosensors: Fabrication of a mini-sensor array for discrimination of small aromatic molecules based on side-chain engineering of naphthalenediimide derivatives. J. Mater. Chem. C 2019, 7, 9726-9734. [CrossRef]

37. Matsunaga, Y.; Yang, J.S. Multicolor Fluorescence Writing Based on Host-Guest Interactions and Force-Induced Fluorescence-Color Memory. Angew. Chem. Int. Ed. 2015, 54, 7985-7989. [CrossRef]

38. Hsu, L.-Y.; Maity, S.; Matsunaga, Y.; Hsu, Y.-F.; Liu, Y.-H.; Peng, S.-M.; Shinmyozu, T.; Yang, J.-S. Photomechanochromic vs. mechanochromic fluorescence of a unichromophoric bimodal molecular solid: Multicolour fluorescence patterning. Chem. Sci. 2018, 9, 8990-9001. [CrossRef]

39. Yang, J.-S.; Swager, T.M. Porous Shape Persistent Fluorescent Polymer Films: An Approach to TNT Sensory Materials. J. Am. Chem. Soc. 1998, 120, 5321-5322. [CrossRef]

40. Yamagishi, H.; Nakajima, S.; Yoo, J.; Okazaki, M.; Takeda, Y.; Minakata, S.; Albrecht, K.; Yamamoto, K.; Badía-Domínguez, I.; Oliva, M.M.; et al. Sigmoidally hydrochromic molecular porous crystal with rotatable dendrons. Commun. Chem. 2020, 3, 118. [CrossRef]

41. Fujii, K.; Sakon, A.; Sekine, A.; Uekusa, H. Reversible Color Switching of an Organic Crystal Induced by Organic Solvent Vapors. Cryst. Growth Des. 2011, 11, 4305-4308. [CrossRef] 
42. Sakon, A.; Sekine, A.; Uekusa, H. Powder Structure Analysis of Vapochromic Quinolone Antibacterial Agent Crystals. Cryst. Growth Des. 2016, 16, 4635-4645. [CrossRef]

43. Yano, Y.; Ono, T.; Hatanaka, S.; Gryko, D.T.; Hisaeda, Y. Salt-cocrystal continuum for photofunction modulation: Stimuli-responsive fluorescence color-tuning of pyridine-modified intramolecular charge-transfer dyes and acid complexes. J. Mater. Chem. C 2019, 7, 8847-8854. [CrossRef]

Publisher's Note: MDPI stays neutral with regard to jurisdictional claims in published maps and institutional affiliations.

(C) 2020 by the authors. Licensee MDPI, Basel, Switzerland. This article is an open access article distributed under the terms and conditions of the Creative Commons Attribution (CC BY) license (http://creativecommons.org/licenses/by/4.0/). 